\title{
Effects of Latent Infection, Temperature, Precipitation, and Irrigation on Panicle and Shoot Blight of Pistachio in California
}

\author{
A. L. Mila, G. F. Driever, D. P. Morgan, and T. J. Michailides
}

Department of Plant Pathology, University of California, Kearney Agricultural Center, Parlier 93648.

Current address of A. L. Mila and G. F. Driever: Department of Plant Pathology, University of California, Riverside 92521. Accepted for publication 12 April 2005.

\section{ABSTRACT}

Mila, A. L., Driever, G. F., Morgan, D. P., and Michailides, T. J. 2005. Effects of latent infection, temperature, precipitation, and irrigation on panicle and shoot blight of pistachio in California. Phytopathology 95:926-932.

Panicle and shoot blight, caused by a Fusicoccum sp., is an economically important disease of pistachio in California. Between 1999 and 2001 , the disease severity was monitored throughout the growing season in 10 pistachio orchards, irrigated with drip, microsprinklers, low-angled $\left(12^{\circ}\right)$ sprinklers, or flood. The effect of temperature, precipitation pattern, irrigation system, and incidence of Fusicoccum sp. latent infection on panicle and shoot blight severity was quantified with a generalized linear model for repeated measures. The number of continuous rainy days in
April and May and the cumulative daily mean temperatures from June to early September had a significant positive effect on panicle and shoot blight of pistachio leaves and fruit. Drip irrigation significantly decreased disease risk. Other factors, such as the number of discontinuous rainy days in April and May, the cumulative deviation from the 30-year average temperature during the dry days of April and May, the incidence of latent infection (only on leaves), and irrigation with microsprinklers or lowangled $\left(12^{\circ}\right)$ sprinklers were weak explanatory variables of panicle and shoot blight severity. Knowledge of panicle and shoot blight risk may contribute significantly to decisions regarding the appropriate application of fungicides, especially in years or fields of low risk.

Additional keywords: Botryosphaeria dothidea, Pistacia vera.
Pistachio (Pistacia vera L.) is a deciduous dioecious plant, characterized by alternate bearing (i.e., producing a large crop one year and a small crop the next). It thrives in climates offering cool, wet winters and long, hot, dry summers (8). Bloom occurs in late March to mid-April depending on the year and the location, with foliage and shoots fully emerging about 2 weeks later. Nutshells are formed by May and kernels are fully developed around July. Harvest begins typically in early to mid-September when fruit fall easily after mechanical shaking of the trees (8). 'Kerman' and 'Peters' are the major commercial pistachio cultivars currently used as female and male trees, respectively, in California. Both cultivars are highly susceptible to panicle and shoot blight.

Panicle and shoot blight, caused by a Fusicoccum sp., anamorph of Botryosphaeria dothidea (Moug.:Fr.) Ces. \& De Not., is an economically important disease of pistachio in California. In 1998, California suffered the highest yield losses caused by panicle and shoot blight. Yield losses of 40 to $100 \%$ have been reported due to severe fruit infection (19). Fruit clusters may be killed within 2 to 3 weeks following infection (14). The pathogen can also cause shell staining, contributing to losses due to low nut quality (30). This Fusicoccum sp. can infect buds, young blossom panicles, leaves, shoots, and fruit clusters of pistachio trees throughout the season (14). The pathogen produces pycnidia which are the main sources of primary inoculum for the disease (14). The teleomorph (B. dothidea that produces airborne ascospores) has not been reported in pistachio (12). Recent investigation of the population structure of Fusicoccum sp. from pistachio orchards in California demonstrated a remarkably low genetic diversity (12).

Corresponding author: T. J. Michailides; E-mail address: themis@ uckac.edu

DOI: 10.1094/PHYTO-95-0926

(C) 2005 The American Phytopathological Society
Temperature, rainfall, and wetness duration are of utmost importance for panicle and shoot blight development (15). Cirrhi containing pycnidiospores are exuded from the pycnidia when adequate moisture is present (20). Pycnidiospores are usually dispersed by splashing or dripping (16). Infected pistachio leaves require continuous wetness duration of at least 9 to $12 \mathrm{~h}$ to develop symptoms, with most lesions recorded on leaves receiving $72 \mathrm{~h}$ of continuous wetness (15). Interrupted wetness periods may further increase the incidence and severity of infected leaves (15). Spores that do not germinate during a wet period develop thick walls, become dark, and remain in this condition after the initial wetness while their germination is postponed during the intermediate dry period until the next wet period occurs (15).

Irrigation with high-angle $\left(23^{\circ}\right)$ sprinklers was associated with high disease intensity because fruit clusters and foliage were exposed to prolonged wetness (16). The disease was initially absent in drip-irrigated orchards, the most common nowadays, and sporadic in flood-irrigated orchards, the least common nowadays (16). Optimum temperature for germination of Fusicoccum spores on potato dextrose agar (PDA) is 24 to $36^{\circ} \mathrm{C}$, whereas disease development on fruit is optimal at 27 to $33^{\circ} \mathrm{C}$ (15). At higher temperatures $\left(36\right.$ to $\left.39^{\circ} \mathrm{C}\right)$, pycnidiospores failed to develop colonies on PDA (15). Similar temperature ranges for infection and mycelial growth of this pathogen have been reported on apple by Kohn and Hendrix (10). Infected pistachio fruit produce more pycnidia at $33^{\circ} \mathrm{C}$ than at any temperature between 5 and $25^{\circ} \mathrm{C}$ (15).

Although California's climate varies considerably between the Sacramento and San Joaquin valleys, generally April and May are months of high rainfall and moderate temperatures $\left(15\right.$ to $\left.19^{\circ} \mathrm{C}\right)$ in both areas. Later, between June and August, rainfall becomes rare to absent and temperature rises progressively so that temperatures between 25 and $33^{\circ} \mathrm{C}$ become frequent (25). In a recent study (1), leaf and fruit samples were found to be latently infected soon after their emergence in late April or early May suggesting 
that spring conditions, especially rainfall, provide conditions favorable for infection of the developing shoots and blossoms by Fusicoccum sp. (7). However, in the same study panicle and shoot blight symptoms on infected shoots became visible after late June when temperatures rise to within the range of optimum growth for Fusicoccum sp. (1).

The pistachio industry in California is based primarily on the female cv. Kerman, which is very susceptible to Fusicoccum sp. The pathogen is difficult to control once it has been established in a pistachio orchard (17). Intense pruning is usually recommended to reduce the inoculum potential in a field. Strobilurin fungicides were registered for panicle and shoot blight of pistachio after the epidemic of 1998 and have been very effective in controlling the disease. Applications are recommended in spring to prevent or reduce the incidence of infection and later in summer (June and July) to prevent symptoms development (unpublished data).

The objective of the present study was to quantify the effects of latent infection, temperature, precipitation, and irrigation systems on panicle and shoot blight severity in pistachio orchards during the growing season. Ultimately, the results of this study will be used to develop a risk assessment system for panicle and shoot blight of pistachio to guide growers in their efforts to control the disease.

\section{MATERIALS AND METHODS}

Disease assessment. Panicle and shoot blight severity was monitored in four orchards in Glenn, San Joaquin, Merced, and Tulare counties in California in 1999 and 2000 and in the orchards of Glenn and San Joaquin counties in 2001. The disease severity was evaluated every 12 to 22 days starting in late May (in 1999) or early to mid-April (in 2000 and 2001) until early September before harvest. The locations were chosen based on the observations of 1998, an epidemic year for panicle and shoot blight in California; at the end of the season, the orchards in Glenn and San Joaquin counties had high incidence (i.e., percentage of blighted shoots) of panicle and shoot blight and the orchards in Merced and Tulare counties had moderate to low disease incidence. Trees were about 20 years old in all orchards. In each orchard, five female single-tree replications that had not received any fungicide treatment were used to monitor panicle and shoot blight severity. The trees were arranged in a randomized complete block design among 20 trees used for fungicide application experiments. In each tree, four branches bearing leaves and fruit were tagged early in the season, as soon as the fruit clusters were formed. At each evaluation, the severity of panicle and shoot blight on each branch was visually assessed using the HorsfallBarratt (H-B) rating scale (9). For the H-B scale, the class numbers corresponding to the estimated severity percentage are $0=0$, $1=0^{+}$to $3,2=3^{+}$to $6,3=6^{+}$to $12,4=12^{+}$to $25,5=25^{+}$to 50 , $6=50^{+}$to $75,7=75^{+}$to $88,8=88^{+}$to $94,9=94^{+}$to $97,10=97^{+}$ to $100^{-}$, and $11=100 \%$. The midpoint severity value was assigned for each class number for the analysis $(1,9)$. Symptomless leaves and fruit were collected from the same branches and on the same dates that disease severity was recorded (that is, at 12- to 22-day intervals from April to September) to assess the incidence of latent infection.

Explanatory variables. Variables investigated in this work are listed in Table 1. Irrigation. Each monitored orchard was irrigated with a different irrigation system: drip in Glenn, microsprinklers in San Joaquin, low-angled $\left(12^{\circ}\right)$ sprinklers in Merced, and flood in Tulare, respectively. In the case of irrigation with low-angled sprinklers, water reached $\approx 0.5 \mathrm{~m}$ above the ground and did not reach the tree canopy. An indicator variable was used to assess the effect of different irrigation systems on panicle and shoot blight severity (21) (Table 1). Flood irrigation was arbitrarily selected as the reference group, so that the effects of other types of irrigation were estimated relative to the effects of flooding. The use of indi- cator variables allows for the data to be pooled together for analysis of all inputs, while differences among subgroups (i.e., irrigation systems) are still distinguishable (21). This approach is very helpful especially in studies with small sample sizes.

Latent infection level. The over night freezing incubation technique (ONFIT) was used to determine the incidence of latent infection in pistachio leaves and fruit $(18,23)$. Samples of 50 leaves and fruit per orchard were collected for the ONFIT procedure approximately every 2 weeks between mid-April (i.e., after bloom) and the end of August. For each sample, leaves and fruit were surface-sterilized in $70 \%$ ethanol for 10 to $15 \mathrm{~s}$ and then in a chlorine solution $(100 \mathrm{ml}$ of $0.525 \%$ sodium hypochlorite and $0.5 \mathrm{ml}$ of Tween 20 per liter of water) for $5 \mathrm{~min}$. The containers were placed in a freezer at $-16^{\circ} \mathrm{C}$ for $20 \mathrm{~h}$ and then incubated at $28 \pm 2{ }^{\circ} \mathrm{C}$ for 10 days. Infection (percentage of leaves or fruit on which Fusicoccum mycelia were present) was evaluated after 10 days of incubation. Infection in each orchard was related to disease severity assessed during the same interval.

Weather variables. Two weather variables were considered: daily precipitation and daily mean air temperature. In our study, the correlations between average temperature and precipitation during April and May ranged from 0.88 to 0.96 for the monitored orchards. Multicollinearity of variables likely increases the variance of parameter estimates in a model and may lead to the inclusion of unimportant variables or the exclusion of important variables. Precipitation and air temperature are usually correlated, for example, temperature is more likely to be below average on rainy days than on dry days (24). Specifying one variable, given the status of the other, allows for the simultaneous incorporation of multiple weather variables in the model (24). Following the technique presented by Richardson (24), we considered precipitation as the primary variable and then daily temperature was conditioned on whether the day was rainy or dry.

Precipitation. In 1998, a record year with respect to the number of days with rainfall, there were 20 to 30 days of measurable rainfall in April and May in Sacramento and San Joaquin valleys. A similar pattern was not observed in any of the years of our study. In 1999 and 2001, there were 5 to 6 days of rainfall, whereas a higher number ( 8 to 11 ) was observed in 2000 , with most days with precipitation concentrated in Sacramento Valley. We introduced the following variables: number of continuous rainy days (summation of a rainy day following a rainy day, $Z_{r / r}$ ) and number of discontinuous rainy days (summation of a rainy day following one or more dry days, $Z_{r / d}$ ). That is, the occurrences of dry and

TABLE 1. Description of variables used to explain panicle and shoot blight severity caused by Fusicoccum sp. on pistachio leaves and fruit in commercial orchards in California

\begin{tabular}{|c|c|c|}
\hline Variable type & Variable description & Definition \\
\hline Irrigation $^{\mathrm{a}}$ & $\begin{array}{l}\text { Drip } \\
\text { Low-angled }\left(12^{\circ}\right) \text { sprinklers } \\
\text { Microsprinklers }\end{array}$ & $\begin{array}{l}\text { Drip } \\
\text { Sprinklers } \\
\text { Microsprinklers }\end{array}$ \\
\hline Infection & Percentage of latent infection & Latent infection \\
\hline Precipitation & $\begin{array}{l}\text { Number of rainy days after a } \\
\text { rainy day } \\
\text { Number of rainy days after } \\
\text { one or more dry days }\end{array}$ & $\begin{array}{l}\mathrm{Z}_{r / r} \\
\mathrm{Z}_{r / d}\end{array}$ \\
\hline Temperature $\left({ }^{\circ} \mathrm{C}\right)$ & $\begin{array}{l}\text { Cumulative deviation from } \\
\text { the } 30 \text {-year monthly mean } \\
\text { temperature during the dry } \\
\text { days of April and May } \\
\text { Cumulative daily mean } \\
\text { temperature from } 1 \text { June until } \\
\text { harvest (September) }\end{array}$ & $\begin{array}{l}\text { Deviance from normal } \\
\text { temp. (April-May) }\end{array}$ \\
\hline
\end{tabular}

\footnotetext{
a Flood irrigation was arbitrarily selected as the reference group, so that the effects of other types of irrigation were estimated relative to the effects of flooding: 0-no drip, 1-drip; 0-no low-angled sprinklers, 1-low-angled sprinklers; and 0-no microsprinklers, 1-microsprinklers.
} 
wet days are modeled as a first-order Markov chain, where it is assumed that the occurrence of rain on the $i$ th day depends only on whether day $i-1$ was wet or dry (27). A day with total rainfall of $0.2 \mathrm{~mm}$ or more was considered a rainy day (24).

Temperature. In 1998, the daily mean air temperature was below the 30-year average during April and May. During the last 2 weeks of July and the first 2 weeks of August daily temperature was substantially higher than the corresponding 30-year average, ranging between 25 and $32^{\circ} \mathrm{C}$ (Fig. 1). In 1999, temperatures in April and May were near average, whereas daily summer temperatures were lower than the 30-year average. In 2000, daily temperatures in early April and June and in 2001, daily temperatures in late May and early June were high but remained moderate for the rest of the season (Fig. 1). In the final model, two temperature variables, the cumulative daily deviation from the 30 -year average temperature during the dry days of April and May and the cumulative daily mean temperature from 1 June until harvest (mid- to late September), were chosen to explain the effect of temperature on disease severity. These two variables had weak correlation with the precipitation variables $\left(R^{2}<0.16\right)$ that allowed their simultaneous use in the model. Together, these variables yielded models with the highest explanatory power.

Weather data were obtained from the National Oceanic and Atmospheric Administration (NOAA) online through the National Climatic Data Center (NCDC) in Asheville, NC for the orchards in Glenn, San Joaquin, and Tulare counties and from the California Irrigation Management Information System (CIMIS) for the orchard in Merced County. Data included daily mean air temperature and precipitation for the months of April, May, June, July, August, and September. NOAA and CIMIS weather stations can measure $0.2 \mathrm{~mm}$ or more of rainfall per hour. Orchards in Glenn, San Joaquin, Merced, and Tulare counties were 7.5, 10, 15, and $6 \mathrm{~km}$ from the closest NOAA or CIMIS weather station, respectively.

Data analysis. A mixed linear model analysis of variance (PROC-GLM; Statistical Analysis Systems, version 8.0; SAS Institute, Cary, NC) was used to examine the effects of different orchards and years on incidence of latent infection or disease severity on leaves and fruit. The logit transformation was used to linearize the data and stabilize variances (26). For the repeated measures, it was assumed that there was an unstructured correlation for the latent infection (\%) or disease severity over time (11). $F$ tests were used to determine if effects or their interactions significantly affected the logit of latent infection (\%) or disease

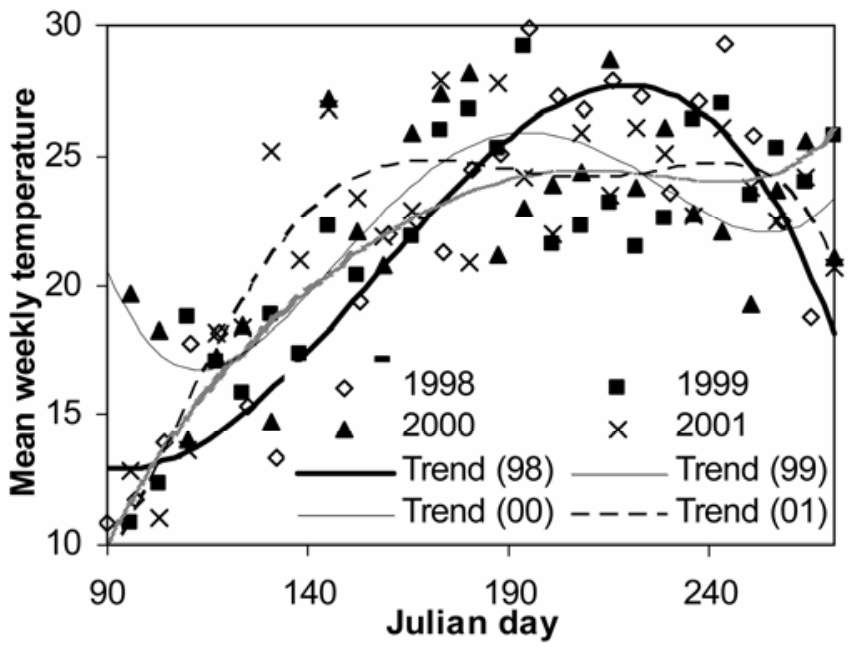

Fig. 1. Weekly mean air temperature with fitted polynomial trends in the pistachio orchard in Glenn County from April to September recorded by the nearest National Oceanic and Atmospheric Administration (NOAA) weather station between 1998 and 2001. Trends were similar for all four pistachio fields that were monitored from 1999 to 2001. severity. Explanatory variables were tested for possible correlation (PROC-CORR; SAS Institute).

Severity of panicle and shoot blight on leaves or fruit was logittransformed $(\ln [p /(1-p)])$ and modeled as a function of weather variables, latent infection (\%), and irrigation: $\ln (p /(1-p))=b_{1} X_{1}+$ $b_{2} X_{2}+\ldots+b_{i} X_{i}(1)$, where $b_{i}$ 's are parameters to be estimated by maximum likelihood. The GENMOD procedure (SAS Institute) was used. Because measurements of panicle and shoot blight severity were repeatedly taken from the same trees in each orchard during a growing season, measurements are likely to be correlated and repeated measures analysis can be used to account for the correlation (22). One way to do that is by modeling the covariance structure of an individual's response (in this case, disease severity). In GENMOD procedure this can be done with generalized estimating equations (GEEs) (6). There are several alternative correlation structure specifications available, such as the socalled exchangeable correlation structure (when it is assumed that measurements from the same field are equally correlated regardless of the length of time between them) and the autoregressive structure (when it is assumed that measurements closer in time are more correlated than measurements at times farther apart) (11), which were tested in the present study. Because the assumption of independence is no longer valid, initial parameter estimates were based on a generalized linear model, and these estimates were used as initial values for the GEE parameter estimation. $P$ values of parameter significance were calculated using the $Z$ score (11).

The deviance, that is, the summation of differences between observations and their predictions based on the model, was used to assess model fit (13). A deviance that is approximately equal to model degrees of freedom is an indication of a good model fit (13). Alternatively, the deviance may be compared with its asymptotic chi-square expectation (with equal degrees of freedom) to calculate the corresponding $P$ value. A $P$ value of $>0.05$ indicates that the specified model fits the data reasonably well. McCullagh and Nelder (13) suggest the visual examination of residuals along with the use of deviance to assess model fitness. Here, model fit was assessed using both deviance and the visual examination of residuals.

Model verification and validation. Here we followed the approach introduced by Chen and George (4). One hundred bootstrap samples were generated by resampling the residuals, generating new observations and using the same procedure as the original analysis was used to fit the model and estimate the parameters. Generally, important variables (i.e., significantly different than 0) should be included in most of the replications and the inclusion frequencies may be used as criteria for the importance of a variable (strong, weak, and unimportant variables when variables are included almost always, some, and a few times, respectively) (4).

\section{RESULTS}

Incidence of latent infections. There were significant differences $(P=0.0007)$ in the percentage of infected organs (leaves or fruit) among orchards. The interaction between year and orchard was significant as well (Table 2). The highest incidence of latent infection was recorded from the orchards of Glenn and San Joaquin counties in 2000. There were no significant differences among sampling dates $(P=0.07)$ and organs $(P=0.83)$ within an orchard during a season but there were significant differences among years (Table 2, significant interaction between year and time).

Panicle and shoot blight severity. There was significant $(P<$ 0.0001 ) year effect (Table 2) on panicle and shoot blight severity. Among the 3 years, average disease severity was highest in 2000 when the first symptoms appeared in mid-May, slowed down slightly in July, and progressed rapidly again in late August. Generally, symptoms appeared earliest in 2001 and latest in 1999. 
There was a significant interaction between year and organ $(P=$ 0.0016) (Table 2). Disease severity was higher in fruit than in leaves in 2000 and 2001, while the opposite was observed in 1999 $(P=0.002$ for interaction of year with organ). In 2000, the highest average disease severity was recorded on fruit clusters in the orchards in Glenn and San Joaquin counties $(P<0.0001$ for the year-time interaction) (Table 2).

Correlations between explanatory variables. The correlation analysis showed that there was a significant positive correlation between percentage of latent infection and number of continuous rainy days $(P<0.0001$ for the leaves and $P<0.0001$ for the fruit). Similarly, the number of discontinuous rainy days was significantly negatively correlated with the cumulative deviation from the 30-year average temperature during the dry days of April and May $(P<0.0001)$ (Fig. 2).

Factors affecting panicle and shoot blight severity. Leaves. In the original model, the continuous and discontinuous days with rainfall during the growing season and the cumulative daily mean temperature for the months of June until September (harvest) were positively correlated with disease severity. The cumulative deviation during the dry days from the 30-year average temperature for April and May was not significantly associated with the disease severity on leaves (Table 3). Drip irrigation and microsprinklers decreased disease severity (i.e., negative parameter estimates), whereas sprinklers increased panicle and shoot blight severity (i.e., positive parameter estimate) compared with flood which was used as the reference irrigation system (Table 3). Surprisingly, the percentage of latent infection on leaves was not a significant predictor of disease severity. Both tested hypotheses for the covariance structure, the exchangeable and the first-order autoregressive correlation, gave very similar results.

The 100 bootstrap replications demonstrated that only three variables (drip irrigation, number of continuous rainy days, and the cumulative daily temperature from 1 June until harvest in September) were strong explanatory variables (that is, they were included always in the model) of panicle and shoot blight severity. The discontinuous days of rain, irrigation with low-angled sprinklers, or microsprinklers were weak variables (inclusion frequency 31 to $44 \%$ ) (Table 4). When only the strong variables were included in the analysis, the parameter estimates were very close to those estimated with the original regression. The estimated deviance and the visual examination of residuals suggested good model fit, almost equal to the original analysis (Table 5). Regression of estimated versus observed disease severity using only the strong variables showed very good correlation between observed and fitted values (Fig. 3A). $R^{2}$ was $0.88(P<0.0001)$, and the intercept and the slope were not significantly different from zero and one, respectively, and were not different from the original model.

TABLE 2. Effects of orchard, organ (i.e., leaves and fruit), sampling dates (time), and year on the logit of infection incidence by Fusicoccum sp. and panicle and shoot blight disease severity of pistachio based on a mixed model analysis of variance

\begin{tabular}{lccccc}
\hline & \multicolumn{2}{c}{ Infection incidence } & & \multicolumn{2}{c}{ Disease severity } \\
\cline { 2 - 3 } \cline { 5 - 6 } Effect $^{\mathrm{a}}$ & $F$ & $P>F$ & & $F$ & $P>F$ \\
\hline Orchard & 6.19 & 0.0007 & & 1.57 & 0.20 \\
Organ & 0.05 & 0.83 & & 0.23 & 0.63 \\
Time & 14.98 & 0.07 & & 4.10 & 0.0006 \\
Year & 69.50 & $<0.0001$ & & 23.90 & $<0.0001$ \\
Orchard $\times$ organ & 0.65 & 0.60 & & 0.80 & 0.50 \\
Orchard $\times$ time & 1.51 & 0.09 & & 1.53 & 0.08 \\
Year $\times$ orchard & 15.30 & $<0.0001$ & & 9.30 & $<0.0001$ \\
Time $\times$ organ & 1.50 & 0.18 & & 0.88 & 0.50 \\
Year $\times$ organ & 6.51 & 0.002 & & 6.90 & 0.002 \\
Year $\times$ time & 1.92 & 0.03 & & 4.10 & $<0.0001$ \\
\hline
\end{tabular}

a Time was repeated measures. An unstructured correlation structure was used for an individual's response (i.e., latent infection [\%] or disease severity).
Fruit. Generally, the results for fruit were similar to those for leaves, with the exception of incidence of latent infection. In the original model, three noticeable differences among the factors that were associated with disease severity on fruit versus leaves could be found. From the precipitation variables only the number of continuous rainy days was significant. The cumulative deviation from the 30-year average temperature for April and May during the dry days and the percentage of latent infection significantly affected disease severity on pistachio fruit (Table 6). Microsprinklers was the least favorable irrigation system (parameter estimate had the lowest value) for the disease development. Both tested hypotheses for the covariance structure, the exchangeable and the first-order autoregressive correlation, gave very similar results.
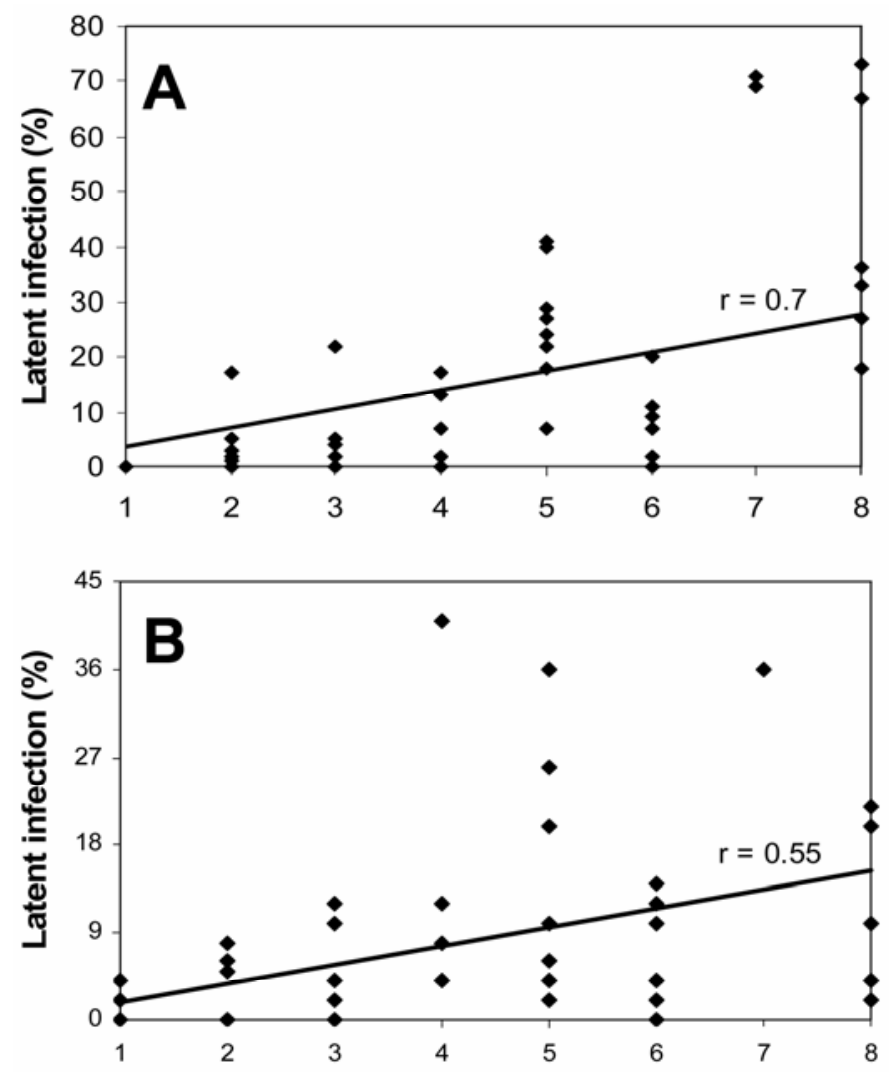

Number of continuous rainy days

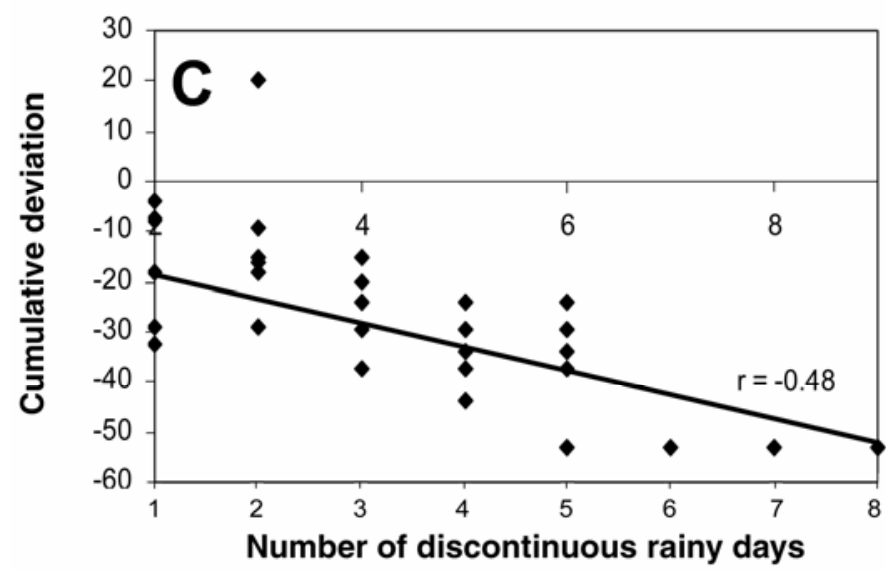

Fig. 2. Correlation $r$ between incidence of latent infection by Fusicoccum sp. in $\mathbf{A}$, leaves, $\mathbf{B}$, fruit and number of continuous rainy days and $\mathbf{C}$, discontinuous rainy days with the cumulative deviation from the 30-year average temperature during the dry days of April and May. 
The 100 bootstrap replications demonstrated that four variables (drip irrigation, percentage of latent infection, number of rainy days after a rainy day, and the cumulative daily temperature from 1 June until harvest in September) were significant in nearly all replications (Table 4). The cumulative deviation from the 30-year average temperature for April and May during the dry days, irrigation with low-angled sprinklers, and microsprinklers were weak explanatory variables (inclusion frequency 39 to $50 \%$ ) (Table 4).

When only the strong variables were included in the analysis, the parameter estimates were very close to those estimated with the original regression. The estimated deviance and the visual examination of residuals suggested good model fit (Table 5). Regression of estimated versus observed disease severity on fruit showed very good correlation between observed and fitted values (Fig. 3B). $R^{2}$ was $0.98(P<0.0001)$, and the intercept and the slope were not significantly different from zero and one, respectively, and were not different from the original model. These results suggest that the most important variables had been selected and the unimportant ones excluded in the original models for leaves and fruit.

\section{DISCUSSION}

This is the first study in which the effects of precipitation and air temperature on the development of panicle and shoot blight in pistachios, caused by Fusicoccum sp., were quantified. Another quantitative study of the effects of temperature and wetness duration on infection by spores of B. obtusa has been reported in

TABLE 3. Parameter estimates for the original and the reduced (including only strong variables as determined with bootstrap selection) generalized linear model with repeated measures for disease severity caused by Fusicoccum sp. on pistachio leaves

\begin{tabular}{|c|c|c|c|c|}
\hline Model & Variables & $\begin{array}{c}\text { Parameter } \\
\text { estimates }\end{array}$ & $\begin{array}{l}\text { Standard } \\
\text { error }\end{array}$ & $P>|Z|$ \\
\hline \multirow[t]{9}{*}{ Original } & Intercept & -6.90 & 0.24 & $<0.0001$ \\
\hline & Drip & -2.23 & 0.047 & $<0.0001$ \\
\hline & Sprinklers & -0.49 & 0.066 & $<0.0001$ \\
\hline & Microsprinklers & -2.10 & 0.23 & $<0.0001$ \\
\hline & Latent infection ${ }^{\mathrm{a}}$ & 0.004 & 0.0041 & 0.28 \\
\hline & $Z_{r / r}^{\mathrm{b}}$ & 0.67 & 0.036 & $<0.0001$ \\
\hline & $Z_{r / d} \mathrm{~b}$ & 0.13 & 0.023 & $<0.0001$ \\
\hline & $\begin{array}{l}\text { Deviance from normal } \\
\text { temp. (April-May) }\end{array}$ & 0.0011 & 0.0006 & 0.34 \\
\hline & $\begin{array}{l}\text { Cumulative daily temp. } \\
\text { (June-September) }^{\mathrm{d}}\end{array}$ & 0.0011 & 0.0002 & $<0.0001$ \\
\hline \multirow[t]{4}{*}{ Reduced } & Intercept & -6.93 & 0.28 & $<0.0001$ \\
\hline & Drip irrigation & -2.10 & 0.16 & $<0.0001$ \\
\hline & $Z_{r / r}$ & 0.72 & 0.032 & $<0.0001$ \\
\hline & $\begin{array}{l}\text { Cumulative daily temp. } \\
\text { (June-September) }\end{array}$ & 0.0011 & 0.0002 & $<0.0001$ \\
\hline
\end{tabular}

a Percentage of leaves with latent infections by Fusicoccum sp. as determined with the over night freezing incubation technique (ONFIT).

${ }^{\mathrm{b}} Z_{r / r}$ and $Z_{r / d}$ indicate number of rainy days that followed a rainy or a dry day, respectively.

${ }^{c}$ Cumulative deviation from the 30-year monthly mean temperature of April and May.

${ }^{\mathrm{d}}$ Cumulative daily mean temperature from 1 June until harvest (September). apples, in a controlled environment experiment (2). In the present study, results are based on field observations and weather data collected from stations located 6 to $15 \mathrm{~km}$ from research sites between 1999 and 2001. Ahimera et al. (1) examined the relationship between the incidence of latent infection and panicle and shoot blight severity on pistachio leaves and fruit and concluded that other factors such as rainfall and temperature may not be ignored for this disease because only a small part of the observed variability in disease severity could be explained by the incidence of latent infection. The present study verifies and supplements that study.

Michailides and Morgan (15) observed 36 to $66 \%$ and 97 to $100 \%$ infection by Fusicoccum sp. in pistachio leaves exposed to continuous wetness for 12 to $24 \mathrm{~h}$ and 48 to $72 \mathrm{~h}$, respectively, which provides an explanation of the significant positive correlation found in our study between percentage of infection and number of days with continuous rainfall. In the same study (15), disease severity on leaves and fruit increased with prolonged (18 to $72 \mathrm{~h}$ ) wetness duration which may explain the significance of continuous days of rainfall to disease severity in pistachio leaves and fruit found in this study. Although pycnidiospores of Fusicoccum sp. can germinate within 1.5 to $2.0 \mathrm{~h}$ after an initial period of wetness (14), a period of $12 \mathrm{~h}$ or longer continuous wetness has been found necessary for penetration and consequently infection through stomata in leaves, lenticels in fruit, or wounds (14). A minimum period of free moisture or high relative humidity is a common requirement for germination and infection by fungal spores (5).

Duration of wetness is a likely reason for the differential effects of irrigation systems on panicle and shoot blight severity on leaves and fruit $(15,16)$. All pistachio orchards in California are irrigated. The disease was initially observed in sprinkler-irrigated orchards, was absent to sporadic in drip-irrigated orchards, and occurred sometimes in flood-irrigated fields (16). The present study was conducted in pistachio fields with history of panicle and shoot blight and irrigated with the four major irrigation systems: drip, flood, microsprinklers, and low-angled $\left(12^{\circ}\right)$ sprinklers. Drip irrigation, although it is related to high establishment cost, is becoming the predominant irrigation system in California because it provides significant water economy and reduced pest risks due to low levels of free moisture and humidity within the orchards. Our results indicated that this might be the case for panicle and shoot blight of pistachio as well. Only drip irrigation was significant and negatively correlated to the disease severity, suggesting that after the introduction of the inoculum in an

TABLE 5. Goodness of fit of the original and a reduced (including only strong variables determined with bootstrap selection) generalized linear model with repeated measures for panicle and shoot blight severity, caused by Fusicoccum sp., on pistachio leaves and fruit during the 1999 to 2001 growing seasons

\begin{tabular}{lcccc}
\hline Model & df & Deviance & $P$ value & Deviance/df $^{\mathrm{a}}$ \\
\hline Leaves (original) & 77 & 95.3 & 0.08 & 1.24 \\
Leaves (reduced) & 81 & 98.6 & 0.09 & 1.22 \\
Fruit (original) & 77 & 67.2 & 0.78 & 0.85 \\
Fruit (reduced) & 80 & 85.2 & 0.32 & 1.06 \\
\hline
\end{tabular}

a A good fit is indicated when deviance/df is approximately equal to 1 .

TABLE 4. Frequency $(\%)$ of parameter estimates significantly different than 0 in 100 bootstrap samples generated by resampling residuals with replacement

\begin{tabular}{|c|c|c|c|c|c|c|c|c|}
\hline Intercept & Drip & $\begin{array}{l}\text { Low-angled } \\
\text { sprinklers }\end{array}$ & Microsprinklers & $\begin{array}{c}\text { Latent } \\
\text { infection }(\%)\end{array}$ & $Z_{r / r}^{\mathrm{a}}$ & $\mathrm{Z}_{r / d}^{\mathrm{a}}$ & $\begin{array}{c}\text { Deviance from } \\
\text { normal }\end{array}$ & $\begin{array}{l}\text { Cumulative } \\
\text { daily temp. }\end{array}$ \\
\hline \multicolumn{9}{|l|}{ Leaves } \\
\hline 100 & 100 & 31 & 44 & 5 & 100 & 44 & 5 & 100 \\
\hline \multicolumn{9}{|l|}{ Fruit } \\
\hline 100 & 90 & 0 & 50 & 90 & 100 & 5 & 39 & 90 \\
\hline
\end{tabular}

${ }^{a} Z_{r / r}$ and $Z_{r / d}$ indicate number of rainy days that followed a rainy or a dry day, respectively. 
orchard, drip irrigation might be the only irrigation system significantly reducing the disease risk.

The cumulative daily mean air temperature for the months of June to September (harvest) was a significant explanatory variable for panicle and shoot blight severity in both leaves and fruit. Interestingly, the estimated parameter for effect of cumulative daily air temperature for the months of June to September for leaves was not significantly different from that estimated for fruit, indicating that the effect of daily air temperature of summer months may be similar for disease development on leaves and fruit.

The effect of temperature on incidence and development of diseases caused by Fusicoccum sp. has been reported in pistachio (20), apple (10), and bigberry manzanita, hoary leaf ceanothus, and silk tassle (3). These studies are in agreement with our results in which increased summer temperatures were associated with increased disease severity. Summer daily average temperatures in the Central Valley of California usually range between 18 and $33^{\circ} \mathrm{C}$, which is favorable for symptom development, and very rarely reach $36^{\circ} \mathrm{C}$ or higher, a temperature level detrimental to the fungus development. In 1998, a devastating year for the California pistachio industry due to panicle and shoot blight, summer daily temperatures were never recorded above $33^{\circ} \mathrm{C}$; however, temperatures were 25 to $32^{\circ} \mathrm{C}$ for a prolonged period, between the two last weeks of July and two first weeks of August (Fig. 1). At this period, fruit clusters are usually very susceptible to symptom development and, if the temperature range is optimum, fruit clusters may be killed within 2 weeks (14). A similar temperature trend was not observed in any of the 3 years of monitoring and the disease severity was much lower than in 1998 (Fig. 1).

The number of discontinuous days of rainfall and the cumulative daily deviation from the 30-year average temperature during the dry days of April and May were weak explanatory variables for disease severity in leaves and unimportant for disease severity in fruit. Nevertheless, their inclusion to the model, even occasionally, indicates their potential as explanatory variables of panicle and shoots blight severity in pistachio leaves and fruit. Surprisingly, the incidence of latent infection was a significant explanatory variable for the fruit but not for the leaves. This may be explained by the fact that a significant portion of leaves with infections abscise while fruit and rachises with infections are usually retained on the tree (14). Moreover, the strong correlation
( $r=0.7, P<0.0001)$ between the number of continuous rainy days and incidence of latent infection on leaves may imply that latent infection was not included as a significant variable only because part of its significance was explained by the number of continuous rainy days that was always selected in the model.

The incidence of latent infection generally did not change systematically upwards or downwards during a growing season over the 3 years of investigation, although there was some fluctuation of the observed percentage of latent infection. Under field conditions, latent infections will occur when inoculum and susceptible tissues are present and rainfall occurs to disperse the available inoculum. These favorable conditions occur from early April

TABLE 6. Parameter estimates for the full and the reduced (including only strong variables determined with bootstrap selection) generalized linear model with repeated measures for disease severity caused by Fusicoccum sp. on pistachio fruit

\begin{tabular}{|c|c|c|c|c|}
\hline Model & Variables & $\begin{array}{l}\text { Parameter } \\
\text { estimates }\end{array}$ & $\begin{array}{l}\text { Standard } \\
\text { error }\end{array}$ & $P>|Z|$ \\
\hline \multicolumn{5}{|l|}{ Original } \\
\hline & Intercept & -8.74 & 0.38 & $<0.0001$ \\
\hline & Drip & -1.12 & 0.22 & $<0.0001$ \\
\hline & Sprinklers & 0.76 & 0.33 & 0.13 \\
\hline & Microsprinklers & -1.73 & 0.59 & 0.0001 \\
\hline & Latent infection ${ }^{\mathrm{a}}$ & 0.03 & 0.004 & $<0.0001$ \\
\hline & $Z_{r / r} \mathrm{~b}$ & 0.73 & 0.03 & $<0.0001$ \\
\hline & $Z_{r / d}^{\mathrm{b}}$ & 0.083 & 0.088 & 0.48 \\
\hline & Deviance from normal & & & \\
\hline & temp. (April-May) ${ }^{\mathrm{c}}$ & 0.009 & 0.002 & $<0.0001$ \\
\hline & $\begin{array}{l}\text { Cumulative daily temp. } \\
\text { (June-September) }^{\mathrm{d}}\end{array}$ & 0.0015 & 0.0001 & $<0.0001$ \\
\hline \multirow[t]{5}{*}{ Reduced } & Intercept & -8.60 & 0.42 & $<0.0001$ \\
\hline & Drip irrigation & -1.06 & 0.35 & $<0.0001$ \\
\hline & Latent infection (\%) & 0.04 & 0.006 & $<0.0001$ \\
\hline & $Z_{r / r}$ & 0.80 & 0.05 & $<0.0001$ \\
\hline & $\begin{array}{l}\text { Cumulative daily temp. } \\
\text { (June-September) }\end{array}$ & 0.0016 & 0.0002 & $<0.0001$ \\
\hline
\end{tabular}

a Percentage of fruit with latent infections by Fusicoccum sp. as determined with the over night freezing incubation technique (ONFIT).

b $Z_{r / r}$ and $Z_{r / d}$ indicate number of rainy days that followed a rainy or a dry day, respectively.

${ }^{c}$ Cumulative deviation from the 30-year monthly mean temperature of April and May.

${ }^{d}$ Cumulative daily mean temperature from 1 June until harvest (September).
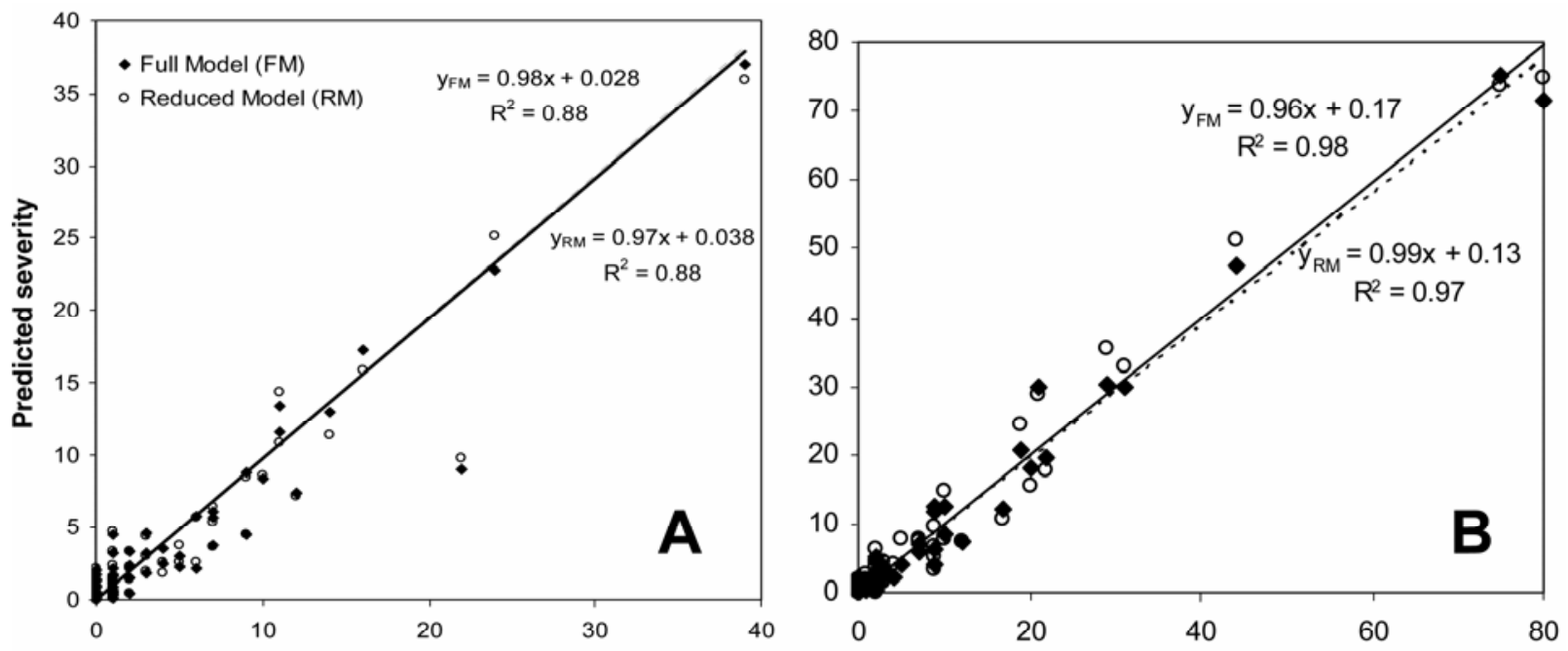

Observed severity

Fig. 3. Comparison of the predicted and the observed severity of panicle and shoot blight caused by Fusicoccum sp. in A, pistachio leaves and B, pistachio fruit during the years of investigation (1999-2001) using the full and the reduced (including only strong variables determined with bootstrap selection) generalized linear model. Model parameter estimates are shown in Tables 3 and 6 for leaves and fruit, respectively. 
(pistachio bloom) to late May/early June (when usually the dry period starts in the Central Valley of California). The data from the end of May 2000 demonstrate this situation. Before that sampling date there were two rain events in Tulare and Merced counties (on 14 and 15 May) and three rain events in Glenn and San Joaquin counties (14 to 16 May) that might have increased the infection levels. Nevertheless, no statistically significant changes of incidence of latent infection on fruit or leaves were observed after early June, a period that coincides with the beginning of the period when rainfall becomes rare in California (data not shown). If this observation of consistent latent infection is confirmed in future studies, it would allow us to reduce the number of samplings to assess occurrence of latent infection during a growing season. It could be possible to determine the best time to perform only one sampling for ONFIT after the beginning of summer when the rainy season is over.

The models were developed with observations collected during years of low disease severity and have not been tested for their accuracy in predicted high disease risk. In 1998, a severe epidemic year, disease data (i.e., percentage of blighted clusters) were collected only at the end of the season and could not be used for validation of the models. However, the models were evaluated for their predictability with new data collected in 2003 and 2004 (unpublished data). In 2003, a year of high panicle and shoot blight, the disease was overestimated in the locations with severe panicle and shoot blight; but, it was estimated accurately in the locations with moderate and low disease severity. Similarly, it was accurately predicted in all monitored locations in 2004, a very low disease severity year (unpublished data). The models are under further validation and modification to account for high disease severity.

Knowledge of disease risk may help farmers to make an appropriate decision on the number and timing of fungicide applications. For instance, in 2003 monitored orchards in northern California received several continuous days of rainfall in April and May that required more than one fungicide applications to reduce the risk of infection. Nevertheless, the percentage of infection in the same orchards was still high $(>10 \%)$, indicating that more applications in summer might be required to suppress possible symptoms development. Indeed, the temperature started increasing significantly after June and more applications in late June and July were necessary to suppress the symptoms development (unpublished data). In 2004, the same locations did not receive any continuous days of rainfall. Thus, the incidence of infection was low and the summer temperature did not increase significantly. The disease severity was not estimated to be high enough to justify a fungicide application at any time during the growing season (unpublished data). Given that the estimated cost of a fungicide application is $\$ 80$ to $\$ 90$ per hectare (7) and treatment of pistachio orchards of several hundreds hectares is not uncommon in California, a warning system for panicle and shoot blight risk may contribute significantly to the reduction of fungicide application costs, especially in years or fields of low risk.

\section{ACKNOWLEDGMENTS}

We thank D. Felts, H. Reyes, K. Robertson, and N. Ahimera for assistance in the field and B. Teviotdale and L. Madden for critically reviewing the first version of the manuscript. We also thank the California Pistachio Industry for financial support of this research.

\section{LITERATURE CITED}

1. Ahimera, N., Driever, G. F., and Michailides, T. J. 2003. Relationships among propagule numbers of Botryosphaeria dothidea, latent infections, and severity of panicle and shoot blight in pistachio orchards. Plant Dis. 87:846-853.
2. Arauz, L. F., and Sutton, T. B. 1989. Temperature and wetness duration requirements for apple infection by Botryosphaeria obtusa. Phytopathology 79:441-444.

3. Brooks, F. E., and Ferrin, D. M. 1994. Branch dieback of southern California chaparral vegetation caused by Botryosphaeria dothidea. Phytopathology 84:78-83.

4. Chen, C. H., and George, S. L. 1985. The bootstrap and identification of prognostic factors via Cox's proportional hazards regression model. Stat. Med. 4:39-46.

5. Clayton, C. N. 1942. The germination of fungus spores in relation to controlled humidity. Phytopathology 32:921-941.

6. Diggle, P. J., Liang, K. Y., and Zeger, S. L. 1994. Analysis of Longitudinal Data. Clarendon Press, Oxford, England.

7. Driever, G. F., Ntahimpera, N., Michailides, T. J., Morgan, D. P., and Felts, D. 2002. Effect of weather conditions on Botryosphaeria blight of pistachio and development of integrated control approaches. Pages 97-99 in: Calif. Pistachio Ind. Annu. Rep. Crop Year 2001-02. California Pistachio Commission, Fresno.

8. Ferguson, L. 1995. The pistachio tree. Pages 7-9 in: Pistachio Production. L. Ferguson, ed. University of California, Davis.

9. Horsfall, J. F., and Barratt, R. W. 1945. An improved grading system for measuring plant disease. (Abstr.) Phytopathology 35:655.

10. Kohn, F. C., and Hendrix, F. F. 1982. Temperature, free moisture and inoculum concentration effects on the incidence and development of white rot of apples. Phytopathology 72:313-316.

11. Lipsitz, S. H., Kim, K., and Zhao, L. 1994. Analysis of repeated categorical data using generalized estimating equations. Stat. Medic. 13:11491163.

12. Ma, Z., Boehm, E. W. A., Luo, Y., and Michailides, T. J. 2001. Population structure of Botryosphaeria dothidea from pistachio and other hosts in California. Phytopathology 91:665-672.

13. McCullagh, P., and Nelder, J. A. 1989. Generalized Linear Models. Chapman \& Hall, London.

14. Michailides, T. J. 1991. Pathogenicity, distribution, sources of inoculum, and infection courts of Botryosphaeria dothidea on pistachio. Phytopathology 81:566-573.

15. Michailides, T. J., and Morgan, D. P. 1992. Effects of temperature and wetness duration on infection of pistachio by Botryosphaeria dothidea and management of disease by reducing duration of irrigation. Phytopathology 82:1399-1406.

16. Michailides, T. J., and Morgan, D. P. 1993. Spore release by Botryosphaeria dothidea in pistachio orchards and disease control by altering the trajectory angle of sprinklers. Phytopathology 83:145-152.

17. Michailides, T. J., Morgan, D. P., and Felts, D. 1998. Spread of Botryosphaeria dothidea in central California pistachio orchards. Acta Hortic. 470:582-591.

18. Michailides, T. J., Morgan, D. P., and Felts, D. 2000. Detection and significance of symptomless latent infection of Monilinia fructicola in California stone fruit. (Abstr.) Phytopathology 90(suppl.):S48.

19. Michailides, T. J., Morgan, D. P., Felts, D., and Chitzanidis, A. 1998. Disease monitoring and prediction of Botryosphaeria blight in California pistachio orchards. Pages 72-76 in: Calif. Pistachio Ind. Annu. Rep., Crop Year 1997-98. California Pistachio Commission, Fresno.

20. Michailides, T. J., and Ogawa, J. M. 1986. Sources of inoculum, epidemiology and control of Botryosphaeria shoot and panicle blight of pistachio. Pages 87-91 in: Calif. Pistachio Ind. Annu. Rep. Crop Year 1985-86. California Pistachio Commission, Fresno.

21. Neter, J., Wasserman, W., and Kutner, M. H. 1989. Applied Linear Statistical Models. Richard D. Irwin, Inc., Homewood, IL.

22. Nita, M., Ellis, M. A., and Madden, L. V. 2003. Effects of temperature, wetness duration, and leaflet age on infection of strawberry foliage by Phomopsis obscurans. Plant Dis. 87:579-584.

23. Ntahimpera, N., Driever, G. F., Felts, D., Morgan, D. P., and Michailides, T. J. 2002. Dynamics and pattern of latent infection caused by Botryosphaeria dothidea on pistachio buds. Plant Dis. 86:282-287.

24. Richardson, C. W. 1981. Stochastic simulation of daily precipitation, temperature, and solar radiation. Water Res. Res. 17:182-190.

25. Rield, H., and Allen, W. W. 1978. Implementing integrated pest management in California. Calif. Agric. 32:8-9.

26. Steel, R. G., Torrie, J. H., and Dickey, D. A. 1997. Principles and Procedures of Statistics: A Biometrical Approach. McGraw-Hill, New York.

27. Todorovic, P., and Woolhiser, D. A. 1974. Stochastic model of daily rainfall. Pages 223-246 in: Proc. Symposium Statistical Hydrology. U.S. Dept. Agric. Misc. Publ. 1275.

28. Warner, M. 1997. Botryosphaeria in pistachios spreading South. Nut Grower 17:4-8. 